\section{TRABALHO INFORMAL E EMPREENDEDORISMO: FACES (IN)VISÍVEIS DA PRECARIZAÇÃO*}

INFORMAL WORK AND ENTREPRENEURSHIP: FACES (IN)VISIBLES OF PRECARIOUSNESS
Andressa Somogy de Oliveira ${ }^{1}$

Carla Appollinario de Castro ${ }^{2}$ Hudson Silva dos Santos ${ }^{3}$
RESUMO: Dentre as diversas mudanças que vêm ocorrendo no mundo do trabalho desde a década de 1970, a disseminação do trabalho informal tem sido central no processo de precarização e de flexibilização dos direitos trabalhistas. No atual estágio do capitalismo, acredita-se que são diversas as tentativas de transferir, do mercado e do Estado para o indivíduo, as responsabilidades/riscos de sua inserção produtiva no mercado de trabalho. Assim, a partir de uma abordagem qualitativa, pautada nas teorias críticas da sociologia do trabalho e do direito (do trabalho), e nas informações sobre o mercado de trabalho no Brasil, o presente artigo pretende analisar as inter-relações estabelecidas entre o trabalho informal e o empreendedorismo, e também a compreensão de seu desenvolvimento e alcance em um contexto de políticas sociais focalizadas.

Palavras-chave: Precarização. Trabalho informal. Empreendedorismo. Flexibilização.
ABSTRACT: Among the many changes taking place in the labor market since the 1970s, the spread of informal work has been central in the process of casualization and flexibility of labor rights. In the current stage of capitalism, it is believed that there are various attempts to transfer, the market and the state to the individual responsibilities / risks of their productive integration into the labor market. Thus, from a qualitative approach, based on the critical theories of sociology of work and (labor) law, and the information on the labor market in Brazil, this article aims to analyze the inter-relations between informal work and entrepreneurship, and also the understanding of its development and scope in the context of targeted social policies.

Keywords: Precariousness. Informal work. Entrepreneurship. Flexibilization.

\footnotetext{
* O presente artigo trata-se de uma primeira aproximação de pesquisas, paralelas e convergentes, de membros do Grupo de Pesquisa sobre Mundo do Trabalho da Universidade Federal Fluminense (GEMUT/UFF).

${ }^{1}$ Mestre pelo Programa de Pós-Graduação em Sociologia e Direito da Universidade Federal Fluminense (PPGSD/UFF), Bolsista da Coordenação de Aperfeiçoamento de Pessoal de Nível Superior (Capes), Pesquisadora do GEMUT/UFF, Professora do Departamento de Direito da UFF - Macaé, andressasomogy@hotmail.com.br.

${ }^{2}$ Mestre e Doutora pelo PPGSD/UFF, Professora do Departamento de Direito da UFF - Volta Redonda e do PPGSD/UFF, Pesquisadora do GEMUT/UFF, carlaappollinario@ig.com.br.

${ }^{3}$ Mestre pelo PPGSD/UFF, Bolsista da Coordenação de Aperfeiçoamento de Pessoal de Nível Superior (Capes), Integrante da Incubadora de Iniciativas da Economia Popular e Solidária da Universidade Estadual de Feira de Santana (IEPS/UEFS), Pesquisador do GEMUT/UFF, Técnico-Administrativo do Instituto Federal de Educação, Ciência e Tecnologia da Bahia (IFBA), hudson_adv@yahoo.com.br.
} 


\section{INTRODUÇÃO}

Dentre as diversas mudanças que vêm ocorrendo no mundo do trabalho desde a década de 1970, a disseminação do trabalho informal tem sido central no processo de precarização e de flexibilização dos direitos trabalhistas. No atual estágio do capitalismo, acredita-se que são diversas as tentativas de transferir, do mercado e do Estado para o indivíduo, as responsabilidades/riscos de sua inserção produtiva no mercado de trabalho, bem como a busca de sua auto-reprodução/sobrevivência e de sua inclusão "cidadã" (ALENCAR, 2007). Nesse contexto de incentivo ao individualismo e de despolitização de problemas sociais (BATISTA, 2002), o empreendedorismo tem sido cada vez mais consagrado como um instrumento necessário de combate ao desemprego e ao trabalho informal.

A partir de uma abordagem qualitativa, pautada nas teorias críticas da sociologia do trabalho e do direito (do trabalho), e nas informações sobre o mercado de trabalho no Brasil, o presente artigo pretende analisar as inter-relações estabelecidas entre o trabalho informal e o empreendedorismo, sob a perspectiva da proteção social, tendo por diretrizes a discussão do empreendedorismo enquanto "uma ideologia ou sub-discurso ideológico dentro de um discurso mais amplo denominado como neoliberalismo" (CASTRO, 2013), e também a compreensão de seu desenvolvimento e alcance em um contexto de políticas sociais focalizadas.

Para responder a questão sobre as aproximações entre trabalho informal e empreendedorismo, por meio de uma revisão de literatura, serão trilhados os seguintes passos:

(1) Apresentação do panorama contextual do trabalho informal e do empreendedorismo, a fim de localizar de onde emerge os fenômenos a serem estudados;

(2) Apresentação do debate conceitual e analítico do trabalho informal e sua interrelação com o processo de precarização, com a finalidade de compreender qual conceito de trabalho informal permite aproximar mais a análise da realidade concreta e, por consequência, entender o significado de sua expressão no capitalismo; 
(3) Análise do empreendedorismo e dos porquês de sua expressividade no mundo do trabalho contemporâneo.

Ao final, espera-se, minimamente, contribuir para o aprofundamento dos estudos sobre as metamorfoses do mundo do trabalho, ao especificar a análise para um dado segmento que adquire expressiva notoriedade no mercado de trabalho do Brasil.

\section{TRABALHO INFORMAL E EMPREENDEDORISMO: UMA VISÃO PANORÂMICA}

As diversas transformações sofridas pelo mundo do trabalho criaram um ambiente instável e incerto, em que o indivíduo tem que ser flexível, polivalente, responsável pelo seu sustento e sobrevivência, e tem seus direitos cada vez mais reduzidos e tratados como privilégios.

Há um pequeno - e cada vez mais reduzido - número de trabalhadores que são qualificados o suficiente para ter algum tipo de estabilidade no trabalho, entretanto a maioria não tem tal qualificação e são precarizados, submetendo-se a atividades informais e, muitas vezes, tensionadas em relação ao Direito, como as ditas atividades ilegais.

É nesse contexto de flexibilização, desmobilização e redução de direitos das trabalhadoras e trabalhadores, que se alastra o número de trabalhadores informais, dentre eles os empreendedores, no Brasil. Dentro de um discurso que perpetra a ideia de que todos podem ser "empresários", "donos do próprio negócio" e ter uma "vida sem chefe", cresce o número de pessoas que, por não ter alternativa e nem acesso a um emprego formal e estável, se tornam empreendedores por necessidade (FALCÃO, 2008), por essa ser a única chance de conseguir seu sustento.

David Harvey traz, em sua obra "Neoliberalismo: histórias e implicações", a discussão de como a palavra liberdade é cooptada para ser base do discurso neoliberal. A liberdade individual e a dignidade humana se tornam parte de um aparato conceitual que "se incorpora a tal ponto ao senso comum que passa a ser tido por certo e livre de questionamento" (HARVEY, 2005, p. 15). Tais ideais são colocadas como a solução para os problemas da humanidade, e sendo eles conceitos que definem os objetivos do neoliberalismo, através da liberdade de mercado e da redução do Estado, quem questiona o neoliberalismo acaba sendo taxado de ultrapassado ou contrário às liberdades: 
A ideia de liberdade "degenera assim em mera defesa do livre empreendimento", que significa a "plenitude" da liberdade para aqueles que não precisam de melhoria em sua renda, seu tempo livre e sua segurança, e um mero verniz de liberdade para o povo, que pode tentar em vão usar seus direitos democráticos para proteger-se do poder dos que detêm a propriedade (HARVEY, 2005, p. 46).

A lógica empreendedora reforça essa "liberdade" que obedece aos desmandos do mercado, que, por sua vez, é colocado como um ente neutro e superior, e alternativa única de saída para garantir que os indivíduos tenham sucesso. Como se a ordem natural das coisas perpassasse pelo capitalismo e pela livre regulação do mercado. A premissa "sem capitalismo não há liberdade" foi tão difundida que muitas vezes deixa de ser questionada, e a contradição é que o "paraíso de realização do indivíduo" se torna o "inferno da ditadura de mercados" (CARCANHOLO, 1998, p. 22).

A partir da década de 1970, há uma intensificação da valorização do capital especulativo em detrimento do capital produtivo, de modo que houve uma flexibilização da produção gerando precarização da força de trabalho e o desemprego estrutural, modificando as políticas de organização e gestão do trabalho (TAVARES, 2002, p. 81).

Com o advento do neoliberalismo e a reestruturação produtiva, a partir da década de 1980, começa a haver uma inserção dos Estados Nacionais no mercado mundial. Essa abertura econômica à concorrência internacional diminui drasticamente a capacidade de diversos países, principalmente os periféricos e "subdesenvolvidos", de desenvolver políticas sociais e de criação de empregos; fato esse piorado pelo alto grau de endividamento desses países (TAVARES, 2002, p. 76). Os altos níveis de desemprego levam a uma naturalização da informalidade que, para Tavares

[...] é vista como fruto da incapacidade de geração de empregos nos mercados formais, passa a incorporar contingentes antes empregados em todos os níveis do mercado formal. Entendemos que o aumento da informalidade pode ser visto como parte do processo de reestruturação produtiva do capital. É no contexto do trabalho precarizado que se desenvolve o trabalho informal (TAVARES, 2002, p. 147).

Neste sentido, é producente reconhecer que a ofensiva neoliberal, que tomou o Brasil a partir da década de 1990, trouxe consigo diversas consequências para os trabalhadores e para o mundo do trabalho. O desassalariamento, os altos níveis de desemprego, a desregulamentação e a relativização dos direitos trabalhistas, a 
desestruturação do mercado de trabalho marcada por uma precarização do trabalho e, por fim, a responsabilização do trabalhador pela sua sobrevivência são algumas das características que marcam o avanço do neoliberalismo e, como uma de suas consequências, o fortalecimento do empreendedorismo enquanto solução para problemas sociais.

A lógica empreendedora no atual contexto de acumulação flexível é marcada pelo individualismo e pela meritocracia, ou seja, o indivíduo é o único responsável pelo seu fracasso ou sucesso. Nessa lógica, caberia ao Estado, portanto, apenas a intervenção a fim de garantir condições mínimas para que o empreendedor cresça e, com ele, cresça a economia do país. No atual contexto, a prática empreendedora tem sido central nas políticas de enfrentamento ao desemprego e à informalidade.

Acredita-se que a reestruturação produtiva do capital, baseada na precarização do trabalho e na flexibilização do uso da força de trabalho, está diretamente ligada à ascensão da informalidade e razão empreendedora (CASTRO, 2013) como solução de problemas sociais, principalmente o desemprego e a cidadania perdida:

\begin{abstract}
Como a proteção individual deixou de ser central, criam-se mecanismos legais que imprimem ao trabalho uma falsa autonomia, marcada pelo "desassalariamento", pela precariedade e pela ausência de comando explícito, como se tais condições fossem suficientes para transformar trabalhadores em proprietários (ALVES; TAVARES, 2006, p. 437).
\end{abstract}

As atividades "autônomas", "independentes", "espontâneas", "empreendedoras" crescem em um contexto de aumento do desemprego e do desassalariamento dos trabalhadores. Com a liberalização do mercado, a proteção social garantida pelo Estado diminui, e o incentivo ao empreendedorismo se torna uma escolha política dentro de uma agenda econômica liberal hegemônica e dominante. A precarização do trabalho e o alijamento do indivíduo da proteção do Estado passam a ser vistos como políticas públicas de emprego e renda, as quais inclusive se utilizam de recursos do Fundo de Amparo ao Trabalhador para serem financiadas, uma faceta nítida da perversidade dessa lógica que precariza o trabalhador, iludindo-o com uma ideia de que agora é "capitalista", "empresário", "patrão de si mesmo", e que o descaso do Estado é, na verdade, independência desse trabalhador. 
É criada uma ilusão de que o Estado está intervindo na questão do desemprego e do aumento da renda, enquanto na realidade a responsabilidade e o risco estão sendo transferidos para os trabalhadores. Como se sua inserção produtiva e cidadã se desse através de um arcabouço ideológico e político que tira essas questões da esfera política e econômica e transfere para a esfera privada, num contexto em que o projeto de desenvolvimento econômico pautado na garantia do emprego é abandonado, num movimento típico do neoliberalismo de individualizar questões que são sociais (ALENCAR, 2007, p. 100).

\section{TRABALHO INFORMAL: PERCEPÇÕES EM MOVIMENTO}

A definição do fenômeno da informalidade é objeto constante de debates teóricos e políticos na literatura especializada da Economia e da Sociologia do Trabalho. As compreensões e os objetivos distintos dos autores sobre a temática e a realidade na qual está inserida revelam as dificuldades de apreensão da realidade social e das alterações sociais, econômicas e políticas, ocorridas desde a origem do conceito nos anos de 1960/70 até o presente início do século XXI (FILGUEIRAS; DRUCK; AMARAL, 2004, p. 212; BARRETO, 2005, p. 54-55).

Neste debate acadêmico, o processo de acumulação global do capitalismo em nível mundial é o principal critério utilizado para se proceder à conceituação do fenômeno da informalidade, destacando-se as seguintes conceituações: Setor Informal, Economia Informal (ilegal, não registrada, submersa ou subterrânea) e atividades não-fordistas.

Antes de iniciar a apresentação das três principais formas de compreensão do fenômeno da informalidade, ressalta-se que as mesmas são as mais utilizadas para a elaboração e interpretação das estatísticas do trabalho informal, sobretudo porque proporcionam objetivos investigativos e referenciais teóricos diferentes.

Datado do final da década de 1960 e início de 1970, a primeira elaboração do conceito Setor Informal é produto do Programa Mundial de Emprego, realizado pela Organização Internacional do Trabalho (OIT) em 1969. Este programa institucional visou indicar proposições para os países subdesenvolvidos sobre estratégias de desenvolvimento econômico, baseadas na criação de empregos, em detrimento do crescimento rápido do 
produto, sendo que, para alcançar tal propósito, faziam-se avaliações da estrutura produtiva e de emprego e renda dos países em estudo (CACCIAMALI, 1982, p. 14-15; BARRETO, 2005, p. 58-59).

O marco importante sobre a delimitação teórica de Setor Informal está no relatório da OIT sobre Emprego e Renda no Quênia (1972), no qual se demonstrava a finalidade de construir uma categoria de análise adequada para descrever as atividades geradoras de uma renda relativamente baixa e que agrupassem os trabalhadores urbanos mais pobres (CACCIAMALI, 1982, p. 14-15). Este relatório também declarava que o Setor Informal decorria do excedente de mão-de-obra advindo do elevado crescimento demográfico (êxodo rural) e da incapacidade de absorção da força de trabalho crescente pelos segmentos modernos (processo de industrialização pós-guerra dos países subdesenvolvidos - substituição de importações).

Em outras palavras, a inexistência de mecanismos institucionais garantidores de uma renda mínima conduzia a população não absorvida a sobreviver das atividades de baixa produtividade, fora da relação assalariada e sem proteção social, apesar dos processos de industrialização tardia dos países subdesenvolvidos, sendo que estas atividades se aproximavam dos setores mais tradicionais da economia. Por consequência, as economias dos países dividiam-se em Setores Formais e Informais (FILGUEIRAS; DRUCK; AMARAL, 2004, p. 213; BARRETO, 2005, p. 59).

Em consonância com as formulações duais (formal/informal e moderno/tradicional) dos estudos da OIT, as "teorias da modernização e da marginalidade" ${ }^{4}$ compreendiam que a informalidade desapareceria com o desenvolvimento e o crescimento econômico.

Em síntese, a "teoria da modernização" ${ }^{5}$, balizada no entendimento de que os países subdesenvolvidos tinham economias polarizadas - por um setor avançado e de

\footnotetext{
${ }^{4}$ Para um maior aprofundamento crítico sobre as teorias dualistas e sua correlação com a realidade brasileira, especificamente a constituição do capitalismo brasileiro, sugere-se o texto clássico de Francisco de Oliveira, A economia brasileira: crítica à razão dualista, em Estudos CEBRAP, n.2, 1972.

5 “De um lado, estava a 'teoria da modernização' que sustentava a tese de que o baixo nível global de capitalização dos países do mundo subdesenvolvido produzia uma estrutura urbana de emprego bastante desequilibrada, contudo esta situação era considerada provisória, caracterizava-se como uma forma de pré-incorporação dos trabalhadores aos empregos assalariados. Nesta mesma direção, surgia a 'teoria da marginalidade' enfatizando as consequências do processo de modernização das economias em desenvolvimento que geravam uma estratificação social em que os trabalhadores não incorporados ao processo produtivo estariam fadados às situações marginais em longo prazo. Por
} 
ponta sucedido da recente industrialização, e, por outro lado, um setor de atividades bastante atrasadas, compostas por migrantes internos -, defendia que a informalidade é um processo transitório e seria superada quando os países saíssem da condição de subdesenvolvimento.

A "teoria da marginalidade", diante das dificuldades de superação do subdesenvolvimento pelos países periféricos, defendia a tese de que certos grupos de trabalhadores seriam inseridos precária e marginalmente, em longo prazo, no mercado de trabalho, em virtude de alguns fracassos do desenvolvimento acelerado dos países de industrialização tardia (BARRETO, 2005, p. 56).

Assim, esta primeira significação do Setor Informal gerou dúvidas e críticas teóricas e empíricas, por: a) não obedecer a algum rigor ou homogeneidade; b) continuar com a abordagem dual e estática, semelhante à concepção de setores moderno/tradicional, que não apresentava a complexidade da dinâmica do processo da produção e do emprego, e que tornava os dois setores (formal e informal) e suas respectivas estruturas e dinâmicas independentes entre si; c) associar o Setor Informal diretamente aos segmentos mais pobres e atrasados da população ocupada; d) não considerar a forma de inserção do trabalhador na produção (FILGUEIRAS; DRUCK; AMARAL, p. 213).

Neste sentido, fundamentado em Oliveira (1972), Barreto (2005) refere-se às diretrizes gerais da visão dualista sobre o Setor Informal, salientando que

[...] não se pode atribuir ao movimento das taxas demográficas a produção de excedentes de trabalhadores na economia dos países marcados pela informalidade, muito menos se pode considerar que o rápido crescimento urbano nestes países decorre de um inchaço do setor terciário ou setor de serviços. 0 setor de serviços que se forma nestes países, marcados majoritariamente por relações informais de trabalho tem seu tamanho, forma e característica estreitamente ligadas ao tipo de acumulação do capital que se forma de acordo com as singularidades históricas de cada nação. [...] O setor de serviços que se forma, sustentado basicamente em relações informais de produção, não se contrapõe, nem concorre com o setor industrial, ao contrário, contribui com o processo de reprodução do capital, atuando, de um lado como exército industrial de reserva e de outro, como escoador de mercadorias da indústria [...] (BARRETO, 2005, p. 64).

esta ótica, o trabalho informal era considerado marginal, desintegrado da estrutura produtiva, não exercendo nenhuma função na estrutura econômica da sociedade. Portanto, estas duas teorias operam com dualismo estrutural que opõem 'tradicional' e 'moderno', 'marginal' e 'integrado' (DRUCK; OLIVEIRA, 2007, p. 03). 
Para buscar a superação das fragilidades teóricas em meados dos anos 1970, a reelaboração do conceito de Setor Informal atrelou-se às relações do trabalhador com os meios de produção, sendo definido como

[...] um conjunto de atividades e formas não tipicamente capitalistas, caracterizadas em especial por não terem na busca do lucro o seu objetivo central e por não haver uma separação nítida entre capital e trabalho, ou seja, o produtor direto, de posse dos meios de produção, executa e administra a atividade econômica, com o apoio de mão-de-obra familiar e/ou alguns ajudantes (FILGUEIRAS; DRUCK, AMARAL, 2004, p. 213).

Esta definição, enquanto categoria analítica alternativa à dicotomia setores moderno/tradicional, considera como parâmetro a forma de organização da produção pelas pessoas e firmas, caracterizando os estabelecimentos informais por possuírem na organização de sua produção um pequeno número de trabalhadores (remunerados e/ou membros da família), pouco capital e uso de técnicas pouco complexas e intensivas de trabalho (CACCIAMALI, 1982, p. 16-17; CACCIAMALI, 2000, p. 155).

Nesta abordagem, o Setor Informal (pequenos produtores e trabalhadores por conta própria) ocupa os espaços de produção não capitalistas e subordina-se ao processo mais geral de acumulação. Por conseguinte, submete-se à dinâmica da produção capitalista: perfil de demanda, distribuição de renda, transferências de trabalhadores do setor formal para o informal nos períodos de crise etc. (FILGUEIRAS; DRUCK; AMARAL, 2004, p. 213).

Destarte, os Setores Formal e Informal são componentes interdependentes do processo de acumulação capitalista. A informalidade representa as atividades cuja organização não é tipicamente capitalista (compra e venda de força de trabalho, propriedade dos meios de produção dentre outros), bem como se recompõe de uma forma subordinada e intersticial ao setor formal nos processos de desenvolvimento da produção (BARRETO, 2005, p. 64-65; CACCIAMALI, 1982, p. 26-35).

Este conceito de Setor Informal, formulado para compreender o fenômeno da informalidade, foi elaborado num contexto pós-guerra, no qual o desenvolvimento do Estado de Bem-Estar Social nos países centrais propiciava a expansão das atividades capitalistas organizadas. Desta forma, os setores privado e público eram incentivados a 
criar postos de trabalho, respaldados na legalidade das relações de trabalho (FILGUEIRAS; DRUCK; AMARAL, 2004, p. 213-214).

Contudo, no final dos anos 1970, a crise do padrão fordista/taylorista ${ }^{6}$ e do Estado de Bem-Estar Social (altas taxas de desemprego, desaceleração das economias, aumento da inflação etc.) e as respostas político-econômicas para esta conjuntura (implementação do processo de reestruturação produtiva e programas de liberalização econômica) desestruturaram as relações de trabalho predominantes até o presente momento nos países centrais capitalistas.

Tal desestruturação permitiu na época o surgimento de atividades não regulamentadas pela legislação vigente (subcontratação, terceirização, cooperativismo, estagiarização etc.) e a redução do contingente de trabalhadores assalariados e socialmente protegidos (FILGUEIRAS; DRUCK; AMARAL, 2004, p. 213-214; BARRETO, 2005, p. 66). Com essa rearticulação na estrutura produtiva, surge a necessidade de (re)definição da informalidade ante à imprecisão da divisão da economia em Setores Formais e Informais e às alterações na conjuntura político-econômica.

Desse modo, o termo informalidade passou a ser sinônimo de Economia Informal/llegal: “atividades e práticas econômicas ilegais e/ou ilícitas, com relação às normas e regras instituídas pela sociedade, [...], sendo redefinida, portanto, por um critério jurídico" (CACCIAMALI apud FILGUEIRAS; DRUCK; AMARAL, 2004, p. 214).

Observa-se na definição supracitada que não se confere mais centralidade ao trabalho informal e sua forma de relação com o processo produtivo, mas fundamentalmente à dimensão dos conflitos de legitimidade e regulamentação legal das atividades laborais (DRUCK; OLIVEIRA, 2007, p. 03). Esta (re)significação de informalidade passa a englobar

[...] tanto certas atividades e formas de produção quanto relações de trabalho consideradas ilegais, entretanto não pode ser identificada como um setor da

\footnotetext{
6 "Compreende-se o fordismo enquanto novo padrão de gestão do trabalho e da sociedade (ou do Estado) que sintetiza as novas condições históricas, constituídas pelas mudanças tecnológicas, pelo novo modelo de industrialização caracterizado pela produção em massa, pelo consumo de massa (o que coloca a necessidade de um novo padrão de renda para garantir a ampliação do mercado), pela 'integração' e 'inclusão' dos trabalhadores. Tal inclusão, por sua vez, era obtida através da neutralização das resistências (e até mesmo da eliminação de uma parte da classe trabalhadora - os trabalhadores de ofício) e da 'persuasão', sustentada essencialmente na nova forma de remuneração e de benefícios" (DRUCK, 2001).
} 
economia, uma vez que o trabalho assalariado sem carteira assinada, por exemplo, está presente tanto em empresas e atividades não registradas quanto em empresas capitalistas formalmente constituídas de acordo com as regras vigentes. Desse modo, nesse segundo conceito, o trabalhador informal se insere tanto na estrutura produtiva, quanto pelos mercados de produtos e serviços (FILGUEIRAS; DRUCK; AMARAL, 2004, p. 214).

Ou seja, neste momento (final dos anos 1970), o conceito de informalidade está associado à capacidade de regulação, pelo Estado, das atividades que infringem as diversas normatizações relativas às relações de trabalho (legislação trabalhista, tributária, previdenciária, administrativa dentre outras).

A partir da década de 1990, sobretudo nos países periféricos, diante do processo intenso de reestruturação produtiva e de avanço das políticas neoliberais, principalmente pela flexibilização e precarização nas relações de trabalho, essa segunda conceituação de informalidade demonstra-se insuficiente para a compreensão da complexidade e heterogeneidade deste fenômeno.

Assim, a elaboração do terceiro significado para o trabalho informal passou a reunir tanto a acepção de atividades e formas de produção não tipicamente capitalista (Setor Informal), quanto a de ilegalidade (Economia Informal), denominando-se atividades nãofordistas. Esta denominação refere-se aos trabalhadores que têm uma inserção precária no mercado de trabalho e contrapõem-se àquelas atividades tipicamente fordistas, caracterizadas pelo assalariamento regulado (FILGUEIRAS; DRUCK; AMARAL, 2004, p. 215; BARRETO, 2005, p. 69-74).

O foco da análise desta definição direciona-se para as atividades desenvolvidas pelos trabalhadores nos mercados de bens e serviços e de trabalho, em um contexto de surgimento de novas e reprodução de antigas e precárias relações de trabalho. A dinâmica econômica não assume papel de centralidade no estudo.

Apresentadas as três principais formas de compreensão do fenômeno da informalidade à luz do processo de acumulação capitalista - e suas transformações, reestruturações e crises -, sintetiza-se, assim, que Setor Informal relaciona-se à organização da atividade econômica (capitalista/não capitalista); Economia Informal, à 
natureza jurídica da atividade econômica (legal/ilegal); e atividades não-fordistas, à junção da organização da atividade econômica com a natureza jurídica da atividade econômica.

Observa-se que as apreensões sobre a informalidade possuem critérios diferentes para as suas respectivas definições. A aplicação empírica dos mesmos revela graus diferentes de importância do trabalho informal para o conjunto do sistema produtivo, pois cada um dos critérios engloba distintas categorias de pessoas ocupadas e diferentes dimensões do mercado de trabalho. A não utilização de critérios para compreender a informalidade implica numa definição genérica deste fenômeno e, por conseguinte, uma camuflagem da realidade.

Deste modo, destaca-se que, na investigação empírica das qualificações de informalidade, a utilização da definição Setor Informal evidencia a menor ou maior heterogeneidade do mercado de trabalho, ou seja, a amplitude das relações de produção e distribuição não tipicamente capitalista articuladas, direta ou indiretamente, ao processo de acumulação capitalista e a importância do emprego e grau de difusão das relações capitalista no conjunto do sistema produtivo; a de Economia Ilegal/informal demonstra a capacidade de regulamentação pelo Estado das atividades econômicas e do acesso dos trabalhadores ocupados aos direitos sociais; a de atividades não-fordistas aponta a amplitude e grau da precarização existente no mercado de trabalho (FILGUEIRAS; DRUCK; AMARAL, 2004, p. 227-228).

As três conceituações, apesar de estarem relacionadas à precariedade das atividades econômicas e das formas e relações de trabalho, possuem limitações para captar as várias expressões heterogêneas entre si, existentes na realidade da informalidade, a citar os trabalhadores assalariados sem carteira, os trabalhadores domésticos, os autônomos, os donos de negócio familiar.

Todavia, em consonância com Filgueiras, Druck e Amaral (2004), o conceito de atividades não-fordistas sobre a informalidade abarca mais a dimensão deste fenômeno (trabalhador familiar, dono de negócio familiar, empregado doméstico, assalariado sem carteira, trabalhador autônomo e empregadores que não recolhem para a previdência), pois apenas não apreende as atividades/relações de trabalho capitalistas registradas 
(trabalhadores assalariados com carteira, assalariado público e empregadores que recolhem para a previdência social).

[...] dos três, o conceito mais adequado de informalidade, enquanto expressão do processo de precarização do trabalho, é aquele que a define a partir das atividades não-fordistas em razão da própria definição de precarização explícita, que abarca tanto indicadores que refletem situações econômicas específicas (desfavoráveis) próprias das atividades econômicas não capitalistas vis-à-vis as capitalistas (como a instabilidade da demanda e do rendimento e longas jornadas de trabalho, por exemplo), quanto indicadores que expressam situações particulares (desfavoráveis) das atividades não regulamentadas vis-à-vis as regulamentadas (como a impossibilidade de acesso ao seguro-desemprego e à aposentadoria, inexistência de férias remuneradas e interrupção do fluxo de rendimentos em razão de doença, por exemplo) (FILGUEIRAS; DRUCK; AMARAL, 2004, p. 228).

Assim, depois de apresentadas as principais formas de conceituação do fenômeno da informalidade, contexto de elaboração e suas diferentes percepções sobre o trabalho informal, para fins deste trabalho, adota-se a significação de atividades não-fordistas dada ao trabalho informal, por possibilitar maior amplitude de análise do processo de precarização das relações de trabalho, no qual, notadamente, o trabalho informal transversaliza vários dos seus indicadores, por exemplo a condenação e descarte do Direito do Trabalho.

\section{EMPREENDEDORISMO: UM CONTO DO “Patrão... DE SI MESMO”}

A centralidade que o empreendedorismo tem alcançado no atual momento do capitalismo, enquanto maneira de enfrentar o desemprego está diretamente ligada a um retorno à visão do indivíduo enquanto único responsável por seu sucesso ou fracasso. 0 neoliberalismo tem a liberdade e a individualidade como seus principais pilares. Prega-se a lógica do "cada um por si" e do não-intervencionismo, confiando na neutralidade do mercado enquanto regulador natural da economia. O padrão de sociabilidade baseado na garantia ao emprego, enquanto forma de acesso à renda e inserção social, foi substituído pelo Estado atuando em um papel meramente gerencial de crises e garantidor apenas de condições para que o capital continue crescendo e lucrando, mesmo que para isso o mundo do trabalho se torne cada vez mais precarizado e a força dos trabalhadores seja mitigada. 
A figura do "empreendedor" surge antes da teorização do "neoliberalismo". Em 1912, o economista Joseph A. Schumpeter usou o termo para definir os indivíduos que realizaram os "empreendimentos de novas combinações" denominados "empresas" (CASTRO, 2012, p. 6). Em 1942, Schumpeter tratou novamente do tema ao identificar

como característica inerente ao sistema capitalista de produção de mercadorias, um processo que ele denominou de 'destruição criadora', por meio da qual o empreendedor assume papel relevante no desenvolvimento de novos produtos, novos métodos e novos mercados, capacidade que auxilia a criação de novas organizações, assim como a revitalização de organizações já existentes (CASTRO, 2012, p. 7).

Durante o período de produção em massa no fordista, o empreendedorismo schumpteriano caiu em desuso e a figura do empreendedor deixou de ser vista como central para a manutenção do sistema capitalista. Entretanto, como trazido por Barbosa (2005, p. 84), a ascensão do neoliberalismo traz a figura do empreendedor de volta, reinserida enquanto necessária ao processo de acumulação de capital, justamente quando o mercado se torna mais liberal e os direitos trabalhistas são mais abandonados.

Apesar da atual fase do capitalismo ser marcado por grandes conglomerados, indústrias transnacionais, mercados interdependentes e constantes inovações tecnológicas - o que faz com que o trabalhador seja cada vez mais "substituível" e, em muitas situações, "descartável" -; a desregulamentação e a flexibilização foram tão intensas e geraram, devido ao desemprego estrutural, um contingente tão grande de desempregados, que o empreendedorismo e o trabalho informal são tomados como alternativas para "compor a base da nova cultura do trabalho desvinculada do assalariamento e individualista" (BARBOSA, 2005, p. 85).

Os níveis de emprego e as condições destes são cada vez mais relegados, por um lado, à esfera privada, ligada à qualificação e capacidade do trabalhador, e, por outro, tiradas da esfera pública, da política macroeconômica. Sendo necessário ao neoliberalismo que haja uma certa desigualdade para que a competitividade se acirre e a economia cresça; o desemprego começa a ser visto como imprescindível e inerente, cabendo aos trabalhadores a inserção no mercado de trabalho e a garantia de sua sobrevivência num contexto de precarização, flexibilização e desvalorização do valor da força de trabalho 
(HARVEY, 2008).

A ofensiva neoliberal, que tomou o Brasil a partir da década de 1990, trouxe consigo diversas consequências para os trabalhadores e para o mundo do trabalho. $O$ dessalariamento, os altos níveis de desemprego, a desregulamentação e a relativização dos direitos trabalhistas, a desestruturação do mercado de trabalho marcada por uma precarização do trabalho e, por fim, a responsabilização do trabalhador pela sua sobrevivência são algumas das características que marcam o avanço do neoliberalismo e, como uma de suas consequências, o fortalecimento do empreendedorismo enquanto solução para problemas sociais.

A lógica empreendedora no atual contexto de acumulação flexível é marcada pelo individualismo e pela meritocracia, ou seja, o indivíduo é o único responsável pelo seu fracasso ou sucesso, cabendo ao Estado apenas a intervenção de garantir condições mínimas para que o empreendedor cresça e, com ele, cresça a economia do país. No atual contexto, a prática empreendedora tem sido central na política de enfrentamento ao desemprego.

O que vemos aqui é que a reestruturação produtiva do capital, baseada na precarização do trabalho e na flexibilização do uso da força de trabalho, está diretamente ligada a ascensão da razão empreendedora como solução de problemas sociais, principalmente o desemprego e a cidadania perdida. A personificação dos problemas leva a uma justificativa do desemprego, primeiro como inerente ao sistema capitalista e segundo como responsabilidade do trabalhador. Em uma só jogada, se desresponsabiliza o Estado e o empregador e, através da lógica de falsas autonomia e independência, propaga-se um discurso que incentiva o trabalhador a viver na ausência da proteção social, convencendo-o de que agora é um empresário.

As atividades "autônomas", "independentes", "espontâneas", "empreendedoras" crescem num contexto de aumento do desemprego e do dessalariamento dos trabalhadores. Com a liberalização do mercado, a proteção social, que é obrigação do Estado, diminui e o incentivo ao empreendedorismo se torna uma escolha política dentro de uma agenda econômica liberal hegemônica e dominante.

Portanto, é no contexto neoliberal, no qual temos o dessalariamento gritante da 
classe trabalhadora e a renúncia do Estado enquanto garantidor de empregos e prestador de serviços sociais, assumindo as funções de um Estado gerencial (MALAGUTI, 2000), que o empreendedorismo é retomado e enaltecido como uma oportunidade para o trabalhador ser dono do seu próprio negócio. No Brasil essa retomada coincide com uma grave crise de emprego, de 1990 a 2009.

Nesse contexto de informalidade e altos níveis de desemprego, é sancionada a Lei do Microempreendedor Individual, Lei Complementar 128/2008, que criou a figura do Microempreendedor Individual, com o objetivo de "formalizar" os informais e trazer uma solução para o desemprego estrutural. Além da formalização que poderia ser feita pela internet e do registro no Cadastro Nacional de Pessoa Jurídicas (CNPJ), o que facilitaria, por exemplo, a obtenção de empréstimos; o Microempreendedor Individual ainda tem a isenção de alguns tributos federais.

O incentivo ao empreendedorismo e as tentativas de "formalização" visando diminuir os índices de trabalho informal escamoteia a realidade concreta, na qual os trabalhadores buscam o empreendedorismo como única alternativa à sobrevivência, e não como um "sonho" de independência do e no mercado formal.

Dados trazidos por Manoel Malaguti (2000, p. 91) demonstram que o "sonho" em ser independente ou trabalhar por conta própria é falso, pois, em realidade, o "sonho" dos trabalhadores é ter empregos estáveis, assalariados, bem remunerados. Entretanto, vendo esse "sonho" cada vez mais longe e improvável, os trabalhadores se veem sem saída e tornam-se autônomos não por escolha, mas por não ter outra opção e por ver no trabalho por conta própria o único caminho de sobrevivência. $\mathrm{Na}$ realidade brasileira, o empreendedorismo mais presente é o "empreendedorismo por necessidade", que seria aquele em que as pessoas envolvidas vivem em condições pré-capitalistas, praticando atividades de subsistência e sem possuir uma capacidade mínima de inserção na economia (FALCÃO, 2008).

Não sendo a primeira opção nem mesmo o "sonho" dos trabalhadores; além de maximizar a exploração, de acordo com dados trazidos por Malaguti (2000)-, esses trabalhadores chegam a trabalhar uma média de 66,95 horas semanais, o que daria uma jornada diária de quase 14 horas em cinco dias úteis - essa disseminação do 
empreendedorismo faz com que esses trabalhadores explorados acreditem que são patrões, conduzindo “(...) à crença de que todos podem ser capitalistas, quando, na realidade, as atividades denominadas autônomas não conseguem ser nem ao menos uma alternativa ao desemprego" (ALVES; TAVARES, 2006, p. 439).

O resgate da importância do indivíduo e da livre iniciativa não passa de uma "pseudo-individualidade", pois, como afirmado por Castro (2012, p. 17), essa individualidade está intrinsecamente ligada à cadeia produtiva, interessada na reprodução do capital e controlada pelo mercado.

Barbosa (2005, p. 83) também desmascara essa falsa autonomia dos empreendedores demonstrando que a vinculação ao mercado formal continua, seja para fazer o serviço ou produto ser interessante ao mercado, seja para adquirir matéria-prima. É o mercado que dita como o empreendedorismo funcionará e esse “(...) consiste num desdobramento da ideologia e da institucionalidade neoliberal voltada para a liberalização da economia e a quebra das regulamentações sociais".

O que seria então a saída para a superação da pobreza, do desemprego e da exclusão social acaba sendo apenas mais uma maneira do Estado neoliberal se isentar de suas obrigações e de relegar para o âmbito privado problemas que, na realidade, são sociais. O trabalhador individualizado é alijado de seus direitos sociais e da proteção estatal e tem sobre si toda a responsabilidade pelo seu sucesso e inclusão produtiva. 0 empreendedorismo, então, mostra-se como mais uma face perversa do capitalismo, aumentando a pauperização desses indivíduos, iludindo-os com uma ideologia de "patrão de si mesmo" e "todos podem ser empresários" numa tentativa de manter a produção capitalista, o desenvolvimento do capital e a hegemonia dos mercados, deixando de lado os problemas sociais e ignorando as consequências nefastas que a precarização tem trazido para a vida dos trabalhadores.

\section{CONCLUSÃO}

São inúmeras as faces da precarização que se entrecruzam no mundo do trabalho. Coube, aqui, tão somente apresentar dois dos fenômenos, o trabalho informal e o empreendedorismo, que, em aparência, são distintos e compartimentados, mas, em 
essência, são irmanados e imanentes ao mesmo processo de precarização do trabalho; digo, processo de acumulação capitalista, que primordial e incessantemente busca a valorização do valor, a extração cada vez maior de trabalho não pago, por meio de diversos artifícios, inclusive quando transfere formalmente as relações de trabalho do âmbito do direito do trabalho para o direito comercial/empresarial, como ocorre com o empreendedorismo.

Neste sentido, o estudo inter-relacionado do trabalho informal com o empreendedorismo deve se subsidiar de referenciais teórico-metodológicos, a exemplo do conceito de atividades não-fordistas, que permitam compreender a complexidade do mundo do trabalho contemporâneo, de forma a "captar" as expressões e os segmentos compartilhados, mas que em algum momento se associam para produzir outra dinâmica. No caso, por um lado, o trabalho informal com sua "visível" precarização; e, por outro, o empreendedorismo com sua "invisível" precarização, quando formalizado juridicamente, e com sua "visível", quando se torna mais uma manifestação do trabalho informal, ao não está conforme os ditames do direito.

Enfim, tratou-se, aqui, de considerações iniciais apenas, em razão desta produção solidária de conhecimento, no âmbito do GEMUT, buscar expressar os primeiros passos teórico-metodológicos para subsidiar um maior aprofundamento no tema e nos estudos de caso vindouros, que, por sua vez, permitirão a compreensão da complexidade das faces (in)visíveis da precarização do trabalho.

\section{REFERÊNCIAS}

ALVES, Maria Aparecida; TAVARES, Maria Augusta. A dupla face da informalidade do trabalho: "autonomia" ou precarização. In: ANTUNES, R. (Org.) Riqueza e miséria do trabalho no Brasil. São Paulo: Boitempo, 2006. p. 425-444.

BARBOSA, Rosangela Nair de Carvalho. Trabalho e economia solidária: crítica ao empreendedorismo como possibilidade histórica. In: FRANCISCO, Elaine Marlova Venzon e ALMEIDA, Carla Cristina Lima de (Orgs.). Trabalho, território, cultura: novos prismas para o debate das políticas públicas. São Paulo: Cortez, 2007. p. 79-98. 
BARRETO, Théo da Rocha. Trabalhadores informais e desempregados: a precarização como homogeneização "sui generis" na formação dos "sem emprego". Um estudo sobre as trajetórias de trabalhadores informais e desempregados na Região Metropolitana de Salvador, no final do século XX. Dissertação (Mestrado). Universidade Federal da Bahia, 2005.

CACCIAMALI, Maria Cristina. Globalização e processo de informalidade. Economia e Sociedade, Campinas, v. 9, n. 1, p. 153-174, junho, 2000.

CACCIAMALI, Maria Cristina. Um estudo sobre o setor informal urbano e formas de participação na produção. Tese (Doutorado). Universidade de São Paulo, 1982.

CASTRO, Carla Appollinario de. Critica à razão empreendedora: a função ideológica do empreendedorismo no capitalismo contemporâneo. Tese (Doutorado). Universidade Federal Fluminense, 2013.

CACCIAMALI, Maria Cristina; ALVIM, Joaquim Leonel de Rezende; NUNES, Tiago de Garcia; Empreendedorismo tupiniquim: notas para uma reflexão. In: CONINTER, 1, 2012, Niterói/RJ. ANAIS DO I CONINTER. Niterói/RJ: 2012.

DRUCK, Maria da Graça. Terceirização: (des)fordizando a fábrica. Um estudo do complexo petroquímico. Salvador: Boitempo, 2001.

DRUCK, Maria da Graça; OLIVEIRA, Luiz Paulo. A condição "provisória permanente" dos trabalhadores informais: o caso dos trabalhadores de rua da cidade de Salvador. In: Congresso Brasileiro de Sociologia, 13, 2007.

FALCÃO, José de Moraes. O espírito empreendedor e a alma do negócio. Disponível em: http://www.sitedoempreendedor.com.br/artigos.php/downloads/baile.pps? acao=exibir\&id=1007. Acesso em 1/02/2011.

FILGUEIRAS, Luiz A. M.; DRUCK, Graça; AMARAL, Manoela Falcão do. O conceito de informalidade: um exercício de aplicação empírica. Caderno CRH, Salvador, v. 17, n. 41, p. 221-229, maio/ago. 2004.

HARVEY, David. O Neoliberalismo. História e implicações. São Paulo: Ed. Loyola, 2008.

MALAGUTI, Manoel Luiz. Crítica à razão informal: a imaterialidade do salariado. São Paulo: Boitempo; Vitória: EDUFES, 2000.

OLIVEIRA, Francisco. A economia brasileira: crítica à razão dualista. Estudos CEBRAP, n.2, 1972.

OLIVEIRA, Andressa S. de. Favela empreendedora: o empreendedorismo e o desenvolvimento socioeconômico das favelas "pacificadas". Dissertação (Mestrado). Universidade Federal Fluminense, 2016.

SANTOS, Hudson S. dos. O trabalho associado em retalhos: Um estudo da (des)proteção jurídica do trabalho. Dissertação (Mestrado). Universidade Federal Fluminense, 2017.

TAVARES, Maria Augusta. Trabalho informal: os fios (in)visíveis da produção capitalista. Revista Outubro, São Paulo, n. 7, p. 49-60, 2002. 
OLIVEIRA, Andressa Somogy de; CASTRO, Carla

Appollinario de; SANTOS, Hudson Silva dos. Pontes de

Miranda: a ênfase na ciência. RBSD - Revista Brasileira de

Sociologia do Direito, v. 4, n. 3, p. 86-105, set./dez. 2017.

Recebido em: 12/01/2017

Aprovado em: 08/05/2017 